\title{
Analysis and Research on the Modal Experiment of Series- Parallel Hybrid Grinding and Polishing Machine
}

\author{
Xing-tian $\mathrm{Qu}^{1, \mathrm{a}}$, Jia-he $\mathrm{Zhang}^{1}$ and Xin Wang ${ }^{1, *}$ \\ ${ }^{1}$ Jilin University, College of Mechanical Science and Engineering, Changchun 130022, China
}

\begin{abstract}
In order to improve the dynamic performance of the grinding machine and improve the machining precision of the machine tool, a modal experiment is conducted on the complete machine and main sub-structures of the series-parallel hybrid grinding and polishing machine tool according to the basic theory of experimental modal analysis. Also, hammer impulse excitation and varied- time-based sampling methods are adopted to perform experimental modal analysis. Meanwhile, the eigensystem realization algorithm (ERA) is utilized to identify modal parameters, so that the low-order natural frequency, damping ratio and modal shape of the complete machine and its main substructures can be obtained. Based on the analysis of frequency and vibration mode, the beam is a weak link of the machine tool, while an approach to improve the dynamic characteristics of the machine tool structure is proposed to provide a basis for the optimized design of dynamics.
\end{abstract}

\section{Experimental Modal Analysis of the Complete Machine and Substructures}

\subsection{Experimental modal research scheme}

The experimental modal analysis of the series-parallel hybrid machine tool uses the INV3018C signal acquisition analyzer, the INV9824 piezoelectric acceleration sensor, and the DASP. V10 software (engineering version) to sample, calculate, and analyze the results of the machine tool ${ }^{[1-2]}$.

\subsection{Research ideas of experimental mode}

The environmental test modal method with the only output is often adopted for large-scale structural parts to implement despite that in the finite element method deviates calculation results of the setting boundary conditions and material properties from the real mode of the actual object.

According to the special structure of the machine tool, special research idea of experiment modal are designed, as shown in Figure 1.2:

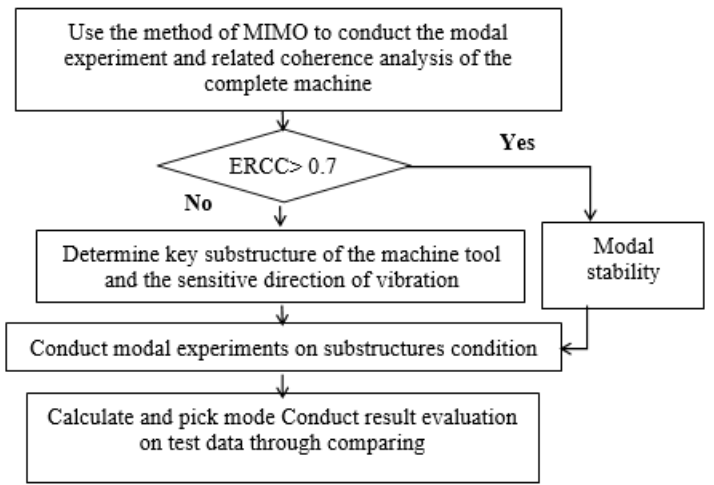

Figure 1.2 Research ideas of experimental mode Annotation: ERCC means encouraging response correlation coefficient

\section{Key Substructure Experimental Mode of Machine Tool}

The substructure modal analysis method is adopted, that is, the substructure mode of main parts in the seriesparallel parts of the machine tool is studied, due to the large structure size of the machine tool, low signal-tonoise ratio of some of the excitations at partial response points, and poor correlation between the input signal and the output signal ${ }^{[3-4]}$. For the gantry-type machine tool, the beam column is often the weak links of the structure $^{[5]}$. In this section, the beam is taken as an example to perform experimental modal analysis of beams, columns, and moving platforms. 


\subsection{Beam modal analysis}

The key to the design of the beam modal experiment is to select measuring points, i.e., to select the excitation point and the response point. The selection process should follow principles such as no false mode generated, the measurement point being in a position that can reflect the geometric characteristics of the structure, the number of measurement points fully reflecting the modal vibration mode of various orders in the analysis range, the origin admittance position avoiding the node for preventing omitting modes and the uniform excitation direction and principal vibration direction. ${ }^{[4]}$ After that, the location of the excitation point, the number and distribution of nodes, and the position and orientation of sensors are determined.

In the modal experiment of the beam, two ends of the beam are fixed, which can be simplified as a simplysupported beam structure. A total of 28 geometric measuring points are selected for the beam modal test. The vertical direction of the beam of the gantry machine tool is error-sensitive. Therefore, Z-direction is set at all geometric measurement points of the beam. In order to facilitate to hammer downwards at both ends of the beam, while the hammering direction for the measuring point in the middle of the beam. Nodes and restraints of the finite element model established by the DASP software are shown in Figure 2.1.

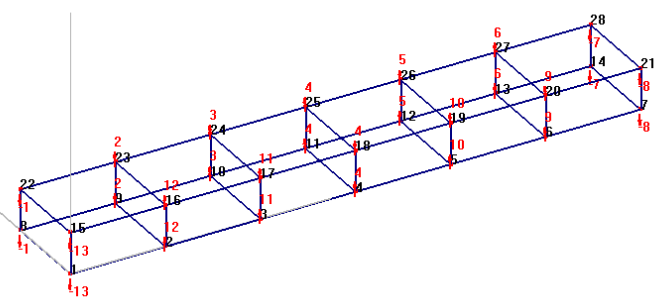

Fig.2.1 Node numbers and constraints of the beam DASP model

\subsection{Calculation of frequency response function}

Due to noise interference in the experiment process, the structure should be excited for three times in turns for average processing in order to reduce the measuring error. In terms of data triggered for multiple times, the input force window is used to eliminate the noise interference signal other than the excitation pulse (the data other than the force window is set to zero); and the response index adding window (avoiding adverse effects on the analysis of the frequency response function caused by response cutting off) can obtain a high SNR, while setting the FRF calculation method. Precision evaluation is conducted on the coherence coefficients of the input and output signals to calculate the fitting degree between the theoretical response waveform and the actual response waveform. ${ }^{[7-8]}$ Figure 2.2 shows the results of three measurements of the time domain signals at response point 1 and excitation point f1. Figure 2.3 shows the FRF between response points and excitation points of multiple inputs and multiple outputs.

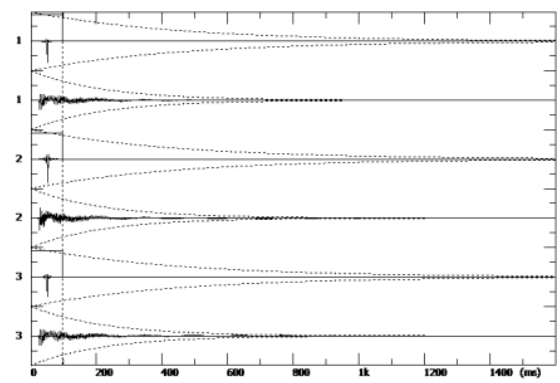

Fig. 2.2 Time domain signal of the response point 1 and the excitation point $\mathrm{f} 1$

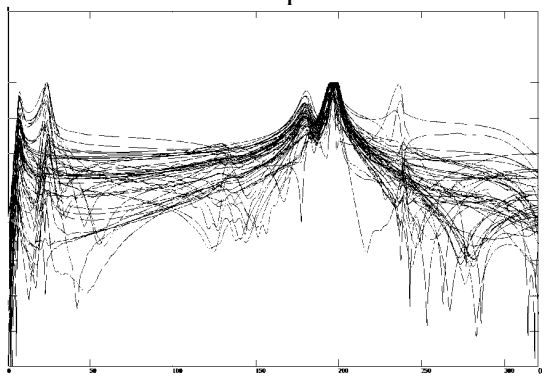

Figure 2.3 Lumped display of MIMO frequency response functions

\subsection{Modal fitting}

The data collected from the experiment are imported into the DASP post-processing software to fit modal parameters using the time domain method and the frequency domain method, respectively. Modal fitting is performed using the PolyLSCF method after order determination. The order determining process is presented in Figure 2.4. After the impulse response function is calculated, the ERA is used to perform modal fitting. Results of the ERA modal fitting are shown in Figure 2.5.

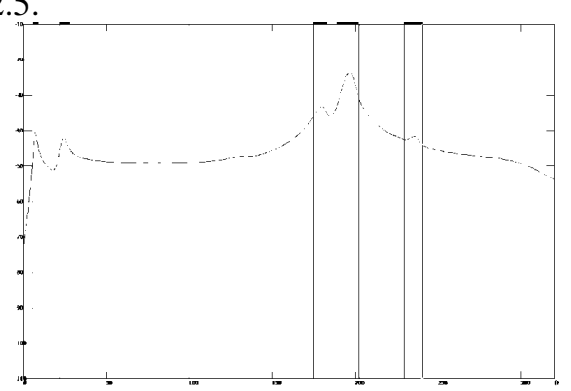

Fig.2.4 Order determination display after the overall average of spectral atlas

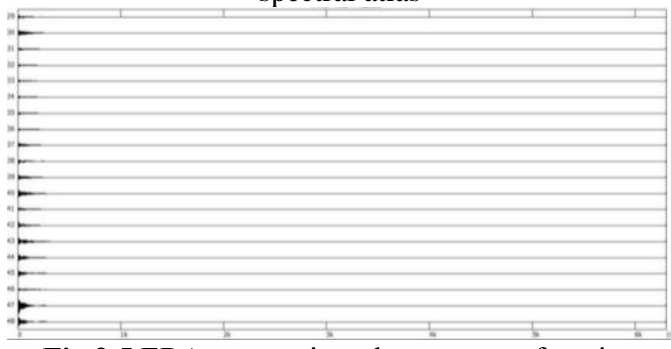

Fig.2.5 ERA request impulse response function

\subsection{Comparison of fitting results}

Modal parameter identification is conducted on the impulse response functions and frequency response functions of experimentally measured 84 points through 
the least squares complex frequency domain method and the ERA. The low-order mode of the machine tool below $300 \mathrm{~Hz}$ should be concerned, since high-frequency exciting force is difficult to generate in the machining process due to low rotation speed of principal moving

Table 2.1 The first four-order modal frequencies and damping ratios of the beam of the machine tool

\begin{tabular}{|c|c|c|c|c|c|}
\hline \multirow{3}{*}{ Order } & \multicolumn{2}{|c|}{ Frequency domain method } & \multicolumn{2}{|c|}{ Time domain method } & \multirow{3}{*}{ Frequency error } \\
\hline & \multicolumn{2}{|c|}{$\begin{array}{l}\text { Least squares complex indicator } \\
\text { method }\end{array}$} & \multicolumn{2}{|c|}{ ERA } & \\
\hline & Frequency/ Hz & Damping & Frequency/ Hz & Damping & \\
\hline First & 23.688 & $1.718 \%$ & 23.963 & $1.272 \%$ & $1.150 \%$ \\
\hline Second & 179.915 & $1.757 \%$ & 179.467 & $1.698 \%$ & $0.250 \%$ \\
\hline Third & 197.246 & $0.309 \%$ & 197.728 & $0.486 \%$ & $0.240 \%$ \\
\hline Forth & 235.397 & $0.251 \%$ & 235.187 & $0.713 \%$ & $0.089 \%$ \\
\hline
\end{tabular}

Error correction is conducted on results obtained from the above two methods. The first-order frequency of the beam structure is about $24 \mathrm{HZ}$ after removing the unstable false mode. Natural frequencies of the first four orders are approximate with the error less than $2 \%$ that is within the acceptable range. The first four modes of vibration of the beam of the machine tool obtained from the experimental mode of the LSCF frequency domain method are shown in Figure 2.6.
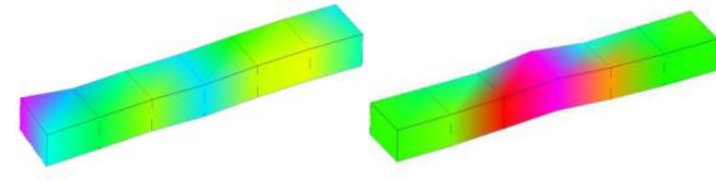

a) First order

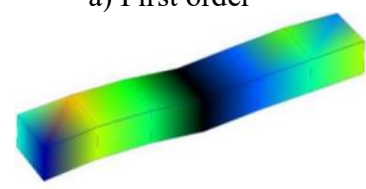

c) Third order b) Second order

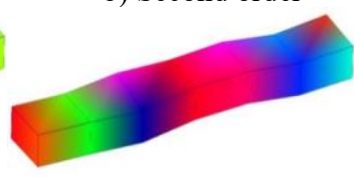

d) Forth order motor and the machining spindle motor of the machine tool. Table 2.1 is the natural frequency and damping ratio of the first four orders obtained by the beam LSCF and ERA method as well as the frequency error obtained by these two methods.

\subsection{Column experimental modal analysis}

During the modal experiment of the column, the same principle as the modal experiment of the beam shall be followed, including no false mode generated and the measuring point that should reflect the location of geometrical characteristics of the structure. After that, the location of the excitation point, the number and distribution of nodes, the position and direction of sensors should be determined. Experiments are performed by the same method to obtain experimental modal parameters of the column. Table 2.2 shows the first four-order modal frequencies and damping ratios of the machine tool obtained by the LSCF and ERA methods of the column and the frequency errors obtained by the two methods.

Fig.2.6 Vibration mode of the beam modal experiment of the first four orders

Table 2.2 The first four-order modal frequencies and damping ratios of the column of the machine tool

\begin{tabular}{|c|c|c|c|c|c|}
\hline \multirow{3}{*}{ Order } & \multicolumn{2}{|c|}{ Frequency domain method } & \multicolumn{2}{|c|}{ Time domain method } & \multirow{3}{*}{ Frequency error } \\
\hline & \multicolumn{2}{|c|}{ Least squares complex indicator method } & \multicolumn{2}{|c|}{ ERA } & \\
\hline & Frequency/ Hz & Damping & Frequency/ Hz & Damping & \\
\hline First & 141.099 & $2.375 \%$ & 144.123 & $1.446 \%$ & $2.098 \%$ \\
\hline Second & 164.383 & $0.660 \%$ & 163.247 & $1.888 \%$ & $0.696 \%$ \\
\hline Third & 225.166 & $1.119 \%$ & 222.794 & $0.756 \%$ & $1.053 \%$ \\
\hline Forth & 234.337 & $0.280 \%$ & 236.597 & $0.313 \%$ & $0.955 \%$ \\
\hline
\end{tabular}

Errors of results of the above two methods are compared. After removing the false mode, the first-order frequency of the column is about $141 \mathrm{~Hz}$ with the error less than $3 \%$ that is within the acceptable range. The first four-order vibration modes of the column obtained by the experimental mode of the LSCF frequency domain method are shown in Figure 2.7. 


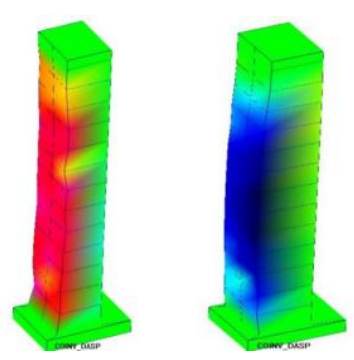

a) First order b) Second order

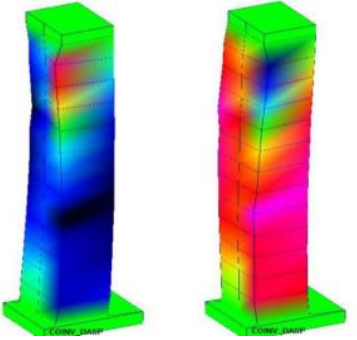

c) Third order d) Forth order

Fig.2.7 Vibration mode of the beam modal experiment of the first four orders

\subsection{Experimental modal analysis of the moving platform}

During the modal experiment of the moving platform, the same principle as the modal experiment of the beam shall be followed, including no false mode generated and the measuring point that should reflect the location of geometrical characteristics of the structure. After that, the location of the excitation point, the number and distribution of nodes, the position and direction of sensors should be determined. Similar experiments are performed on the moving platform to obtain experimental modal parameters of the moving platform. Table 2.3 shows the first four-order modal frequencies and damping ratios of the machine tool obtained by the LSCF and ERA methods of the moving platform and the frequency errors obtained by the two methods.

Table 2.3 The first four-order modal frequencies and damping ratios of the moving platform of the machine tool

\begin{tabular}{|c|c|c|c|c|c|}
\hline \multirow{3}{*}{ Order } & \multirow{2}{*}{\multicolumn{2}{|c|}{$\begin{array}{c}\text { Frequency domain method } \\
\text { Least squares complex indicator } \\
\text { method }\end{array}$}} & \multicolumn{2}{|c|}{ Time domain method } & \multirow{3}{*}{ Frequency error } \\
\hline & & & \multicolumn{2}{|c|}{ ERA } & \\
\hline & Frequency/ Hz & Damping & Frequency/ Hz & Damping & \\
\hline First & 11.053 & $4.586 \%$ & 11.617 & $4.617 \%$ & $4.850 \%$ \\
\hline Second & 60.233 & $1.357 \%$ & 60.398 & $1.412 \%$ & $0.273 \%$ \\
\hline Third & 67.216 & $1.974 \%$ & 68.668 & $1.951 \%$ & $2.140 \%$ \\
\hline Forth & 91.763 & $3.098 \%$ & 89.64 & $3.094 \%$ & $2.313 \%$ \\
\hline
\end{tabular}

Errors of results obtained by the above two methods are compared. Except that the first-order frequency has a large difference, the error ratio is less than 3\% that is also within the acceptable range. The first four-order vibration modes of the moving platform obtained by the experimental mode of the LSCF frequency domain method are shown in Figure 2.8.

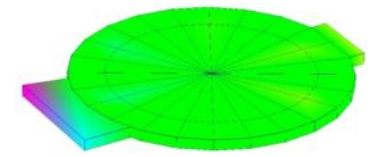

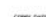

a) First order

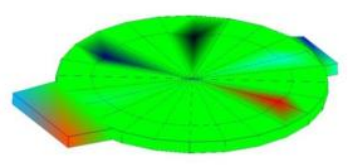

$-\infty$

$\begin{array}{ll}\text { c) Third order } & \text { d) Forth order } \\ \text { Fig.2.8 Vibration mode of the moving platform modal }\end{array}$ experiment of the first four orders

According to modal experimental tests, the stiffness of the moving platform is the worst in all substructures of the machine tool. The first-order natural frequency of the moving platform is only $11 \mathrm{~Hz}$. Since the operating frequency of the B-axis motor is far less than $11 \mathrm{~Hz}$, the first-order natural frequency of the moving platform, no resonance will occur, thus, exerting a minimal impact on the machining production of the machine tool.

The rigidity of the beam is poor. The first-order natural frequency of the beam is $24 \mathrm{HZ}$. As the principal motor is mounted on the beam of the gantry type machine tool, its Z-direction rigidity directly affects the grinding and polishing precision of the blade. Thus, loworder frequency of the beam should be avoided or the rotation speed of the principal motor should be away from the resonant frequency as quickly as possible when selecting the grinding speed.

The rigidity of the column is good. The first-order natural frequency of the column is $141 \mathrm{~Hz}$, which is consistent with the actual situation. The maximum operating speed of the principal motor is $3000 \mathrm{rpm}$, i.e. the excitation frequency is $50 \mathrm{~Hz}$. Therefore, the rigidity of the column is sufficient with no resonance generated, exerting a small influence on the machining of the machine tool.

In summary, the series-parallel hybrid grinding and polishing machine should mainly consider avoiding the spindle speed that is corresponding to the low-order natural frequency of the beam in operation. The true 
dynamic performance of the machine tool can be better reflected through conducting modal analysis on substructures.

\section{Conclusions}

a) The stiffness of the moving was the worst with only $11 \mathrm{~Hz}$ of the first-order natural frequency. As the operating frequency of the B-axis motor was far less than $11 \mathrm{~Hz}$, the first-order natural frequency of the moving platform, no resonance would occur.

b) The first-order natural frequency of the beam was $24 \mathrm{HZ}$ with a poor rigidity.

c) The Z-direction stiffness would directly affect the grinding and polishing precision of the blade because the principal motor was mounted on the beam of the gantry type machine tool. Thus, low-order frequency of the beam should be avoided or the rotation speed of the principal motor should be away from the resonant frequency as quickly as possible when selecting the grinding speed.

d) The rigidity of the column was good. The firstorder natural frequency of the column was $141 \mathrm{~Hz}$, which was far more than $50 \mathrm{~Hz}$, the excitation frequency of the principal motor. Therefore, the rigidity of the column is sufficient with no resonance generated, which was consistent with the actual situation.

\section{References}

1. Wen-ping Cao, Qing-dong Yang. Experimental modal analysis of five-axis combined milling machine[J].Machine Building \& Automation, 37(1):71-73.Li (2008)

2. Yang Li, Qing-dong Yang, Guo-qing Liu. Parameter identification and dynamics of gantry NC machine tool beam part[J].Science, Beijing InformationTechnology University, 25(1):66-69. (2010)

3. Ping Ding, Yan Gu. Application of component modal synthesis(CMS) technique on whole vehicle noise vibration field[J].Shanghai Auto,(11) :22-24 (2007)

4. Xin-Wei Zhang. Component modal synthesis(CMS) technique[J]. Ship Design and Communication ,(1) 2013.

5. Hai-yan Wei, Xian-kui Wang, Ding-wen Yu \& Yufeng Zhang. Experimental Modal Analysis of Horizontal Machine Tools[J]. Machine Tool \& Hydraulics , (5):73-75 (2003)

6. Yao-qiang Wei, Bin Li, Xin-yong Mao, etc. Experimental Modal Analysis of Horizontal Machine Tools[J]. Journal of Huazhong University of Science and Technology(Natural Science Edition),(6):79-82 (2011)

7. Song Shen, Huaiqiao Ying,Suhua Lei; Zengxin Zhao. Modal Test for Yellow River Bridge Exciting with Hamme[J].Journal of Vibration Engineering, 13(3):492-495 (2000)
8. Huibin Li, Huaiqiao Ying.Application of Variable Time Base Technology in Experimental Modal Analysis of Motor Vehicle[J] . Journal of Experimental Mechanics, (3) :347-353 (1993) 